\title{
PTEN EXPRESSION PROFILES IN COLORECTAL ADENOCARCINOMA AND ITS PRECANCEROUS LESIONS
}

\author{
Dariusz WaniczeK ${ }^{1}$, Mirosław Śnietura², JoAnna MłynarcZyk-LiszKa², WojCiech Pigłowski², \\ Agnieszka Kopeć ${ }^{2}$, Dariusz Lange ${ }^{2}$, Marek Rudzki ${ }^{1}$, Jerzy Arendt ${ }^{1}$
}

\author{
${ }^{1}$ Chair and Department of General and Gastrointestinal Surgery, Bytom, Medical University of Silesia, Katowice, \\ Poland \\ ${ }^{2}$ Tumor Pathology Department, Maria Sklodowska-Curie Memorial Cancer Center and Institute of Oncology, \\ Gliwice Branch, Poland
}

\begin{abstract}
The aim of the study was to determine expression of the PTEN suppressor gene in colorectal adenocarcinoma and its precancerous lesions (adenomatous polyps) in correlation with common clinical and histopathological features.

Forty-four patients with adenomatous polyps and 32 with primary adenocarcinoma of the colon or rectum were enrolled in the study. They underwent endoscopic removal of polyps or major surgery and postoperative adjuvant chemo- and radiotherapy depending on staging of the disease. No patient had received chemotherapy and/or radiotherapy before the surgery. PTEN expression was evaluated using immunohistochemical staining on paraffin-embedded specimens and compared to clinicopathological features of tumors.

In colorectal cancers, PTEN expression was found to be significantly lower than in normal intestinal mucosa and adenomatous polyps. That was associated with complete loss of PTEN expression observed more frequently in colorectal cancer, contrary to reduction of PTEN expression occurring mostly in polyps. A correlation between polyp diameter and loss of PTEN was demonstrated as well as between tumor size and TNM advanced stage and PTEN expression.

The obtained results suggest that the PTEN/PI3K/Akt pathway may play an important role in early stages of sporadic colorectal carcinogenesis and reduced PTEN expression in late oncogenesis is associated with some adverse clinical and pathological features.
\end{abstract}

Key words: CRC, PTEN, colorectal cancer, adenomatous polyp.

\section{Introduction}

Colorectal cancer (CRC), one of the most common malignant neoplasms in Western countries, is becoming increasingly frequent in Poland, mostly due to the changes of lifestyle and dietary factors. Currently incidence and mortality rates of CRC are the most dynamic of all neoplastic diseases in the Polish male population [1]. Much evidence has demonstrated that several genetic alterations are involved in the carcinogenetic process of CRC. It is suggested that a subset of these abnormalities concerns the PTEN gene.
Tumor suppressor PTEN (phosphatase and tensin homolog deletion on chromosome 10) is a dual-specific phosphatase that acts as a negative regulator of the PI3K-AKTmTOR pathway, thus controlling a variety of processes related to cell survival, proliferation, and growth. PTEN plays a crucial role in the silencing of signal transduction from membrane growth factor receptors (EGFR, HER-2, IGFR) through the AKT signaling cascade [2]. Somatic PTEN mutations and deletions or epigenetic silencing are common in multiple tumor types, including breast, endometrium, and thyroid, but also tumors of the central nervous system, prostate, lung, melanoma, leukemia and 
lymphoma [3-5]. In many neoplasms PTEN deletion cooperates with other genetic alternations to enhance carcinogenesis and may determine aggressive clinical behavior of a tumor [6]. The role of PTEN in colorectal carcinogenesis was postulated earlier as a component of PTEN hamartoma tumor syndrome (PHTS) - a term encompassing subsets of several clinical syndromes with germline mutations in the PTEN tumor suppressor gene. Estimated lifetime risk of CRC in this group of individuals is $9 \%$ [7]. The prevalence of PTEN mutations in sporadic CRC was reported to range between $1 \%$ and $29 \%$ $[8,9]$. Other mechanisms of inactivation of PTEN in CRC, such as promoter hypermethylation or mutation, have also been described $[10,11]$.

Table I. Clinical and histopathological characteristics of the study groups

\begin{tabular}{|c|c|}
\hline FEATURE & Value \\
\hline \multicolumn{2}{|c|}{ COLORECTAL ADENOMATOUS POLYPS } \\
\hline Age & 64.6 years $(42-83)$ \\
\hline Gender & $\begin{array}{l}\text { Male: } 22 \\
\text { Female: } 22\end{array}$ \\
\hline Location & $\begin{array}{l}\text { Large intestine: } 34 \\
\text { Rectum: } 10\end{array}$ \\
\hline Shape & $\begin{array}{l}\text { Pedunculated: } 15 \\
\text { Semi-sessile: } 1 \\
\text { Sessile: } 19 \\
\text { Lack of data: } 5\end{array}$ \\
\hline \multirow[t]{2}{*}{ Diameter } & $\begin{array}{l}\text { Small (less than } 7 \mathrm{~mm}) \text { : } \\
17(2-6 \mathrm{~mm})\end{array}$ \\
\hline & Large $(\geq 7 \mathrm{~mm}): 27(7-35 \mathrm{~mm})$ \\
\hline Histological type & $\begin{array}{l}\text { Adenoma tubulare: } 36 \\
\text { Adenoma tubulo-villosum: } 3 \\
\text { Adenocarcinoma: } 1\end{array}$ \\
\hline Histological grade & $\begin{array}{l}\text { Low grade: } 28 \\
\text { Medium grade: } 11 \\
\text { High grade: } 2 \\
\text { Lack of data: } 3\end{array}$ \\
\hline \multicolumn{2}{|c|}{ Colorectal cancer } \\
\hline Age & 67.7 years $(42-81)$ \\
\hline Gender & $\begin{array}{l}\text { Male: } 18 \\
\text { Female: } 17\end{array}$ \\
\hline Location & $\begin{array}{l}\text { Large intestine: } 20 \\
\text { Rectum: } 15\end{array}$ \\
\hline Histological type & $\begin{array}{l}\text { Adenocarcinoma: } \\
35 \text { (mucinous: } 3 \text { ) }\end{array}$ \\
\hline Dysplasia grade & G1: $8 ; \mathrm{G} 2: 23 ; \mathrm{G} 3: 4$ \\
\hline $\mathrm{T}$ & $\begin{array}{l}\text { T1: } 4 ; \mathrm{T} 2: 10 \\
\text { T3: 14; T4: } 7\end{array}$ \\
\hline $\mathrm{N}$ & $\begin{array}{l}\text { N0: } 22 \\
\text { N1: } 7 ; \mathrm{N} 2: 6\end{array}$ \\
\hline M & $\begin{array}{l}\text { M0: } 31 \\
\text { M1: } 4\end{array}$ \\
\hline TNM staging & $\begin{array}{l}\text { I: } 14 ; \text { II: } 8 ; \\
\text { III: } 9 ; \text { IV: } 4\end{array}$ \\
\hline
\end{tabular}

The present study aims to investigate the expression profiles of PTEN in colorectal adenocarcinoma and its precancerous lesions - adenomatous polyps - in correlation with the common clinical and histopathological features.

\section{Material and methods}

\section{Study group}

Table I presents clinical and histopathological characteristics of 76 patients included in the analysis. They underwent endoscopic removal of polyps or major surgery and postoperative adjuvant chemo- and radiotherapy depending on disease staging. No patient had received chemotherapy and/or radiotherapy before the surgery. The study included tissue samples of 34 large intestine polyps, 10 rectal polyps and 35 colorectal adenocarcinomas collected during endoscopic or surgical procedures, respectively. Twenty samples of adjacent normally appearing intestinal mucosa served as a control.

\section{Immunohistochemistry}

The PTEN expression pattern was examined immunohistochemically in formalin-fixed, paraffin-embedded tumor specimens collected from all enrolled patients.

The monoclonal, rabbit, anti-human PTEN antibody, clone 138G6, raised against the last 100 C-terminal amino acids of the protein, was used in all analyses (Cell Signaling Technology, Denver). PTEN specificity of that antibody was confirmed earlier, using Western blotting and immunohistochemistry techniques in several cell lines of known PTEN status [12]. Immunostaining was performed according to standard guidelines: four-micrometer-thick sections were cut, mounted on slides, deparaffinized, and rehydrated in xylene and in a graded series of ethanol. Epitope retrieval was carried out for 20 minutes at $98^{\circ} \mathrm{C}$ in TRIS buffer/EDTA $10 \mathrm{mmol} / \mathrm{l}$, $\mathrm{pH}$ 9.0. Endogenous peroxidase activity was inactivated by $3 \%$ solution of hydrogen peroxide for $5 \mathrm{~min}$. Next, primary antibody was applied to the slides (1: 75 dilution in Background Reducing Antibody Diluent, Dako, Denmark) and incubated for 30 minutes at room temperature. Finally, a mixture of polymer conjugated with horseradish peroxidase and affinity-purified goat anti-rabbit Fab' antibody fragments and DAB chromogen was used to visualize the reaction (EnVision + Dako, Denmark). After counterstaining with hematoxylin, specimens were covered with AquaMount (Dako, Denmark) mounting medium.

Staining intensity was evaluated by a pathologist, who was blinded to patient-related clinical information. Scoring was performed according to the relative semi-quantification method described originally by Perren [13] and widely used in many recent studies $[14,15]$. Representative areas of tumor were selected and scored un- 
der original magnification $200 \times$. Slides were classified into two groups, depending on the staining intensity of tumor cells in relation to PTEN expression in adjacent normal-appearing epithelium or stroma, which served also as an internal, positive control. Tumors showing no staining or with staining intensity lower than in corresponding normal tissue were classified as PTEN negative, while those with increased or equal expression were considered to be PTEN positive.

A series of histological preparations of cell lines with known PTEN status [12] served as a positive control. Additional tumor sections, treated as described above but without primary antibody application, revealed no staining (negative control).

\section{Statistical analysis}

Statistical analysis was carried out using the Statistica version 9.0 software suite (StatSoft Inc.) The MannWhitney U test was used to compare clinicopathological and immunohistochemical characteristics. To investigate the correlation between parameters a non-parametric Spearman correlation test was used. P-value equal to or less than 0.05 was considered statistically significant.
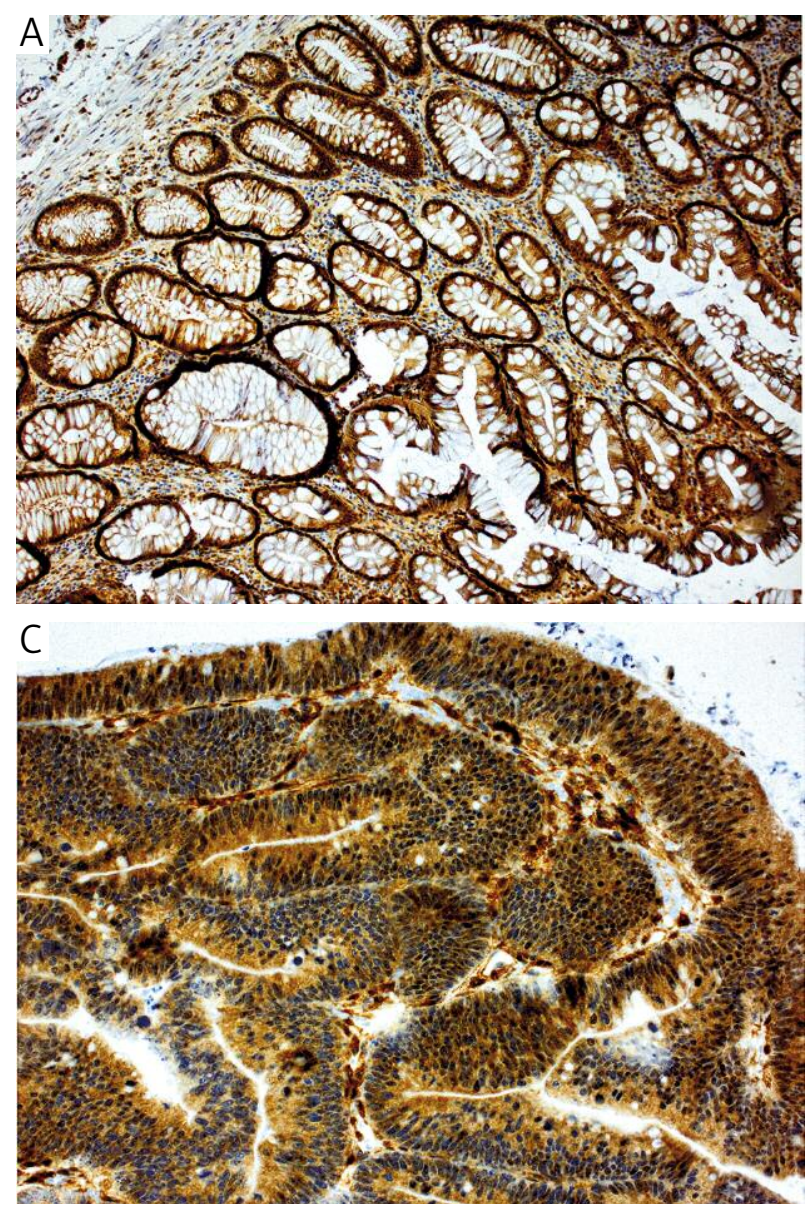

\section{Results}

\section{Expression of PTEN in normal intestinal mucosa}

Diagnostic results were obtained for all cases. The expression of PTEN protein was located mainly in the cell cytoplasm but also in nuclei. Positive, strong cytoplasmic and nuclear expression of PTEN was detected in all 20 normal mucosa specimens (Fig. 1A).

\section{Expression of PTEN in colorectal adenomatous polyps}

Among 44 polyps, normal PTEN expression was observed in 26 cases, that is $59.1 \%$, decreased expression in 16 cases (36.4\%) and no expression in 2 cases (4.6\%) (Fig. 1B). A correlation between PTEN protein expression intensity and polyp diameter was found. Average polyp diameter in the group without PTEN protein expression was $25 \mathrm{~mm}$, while polyps showing decreased or normal expression of that protein had a mean diameter of $12.7 \mathrm{~mm}$ and $6.5 \mathrm{~mm}$, respectively.
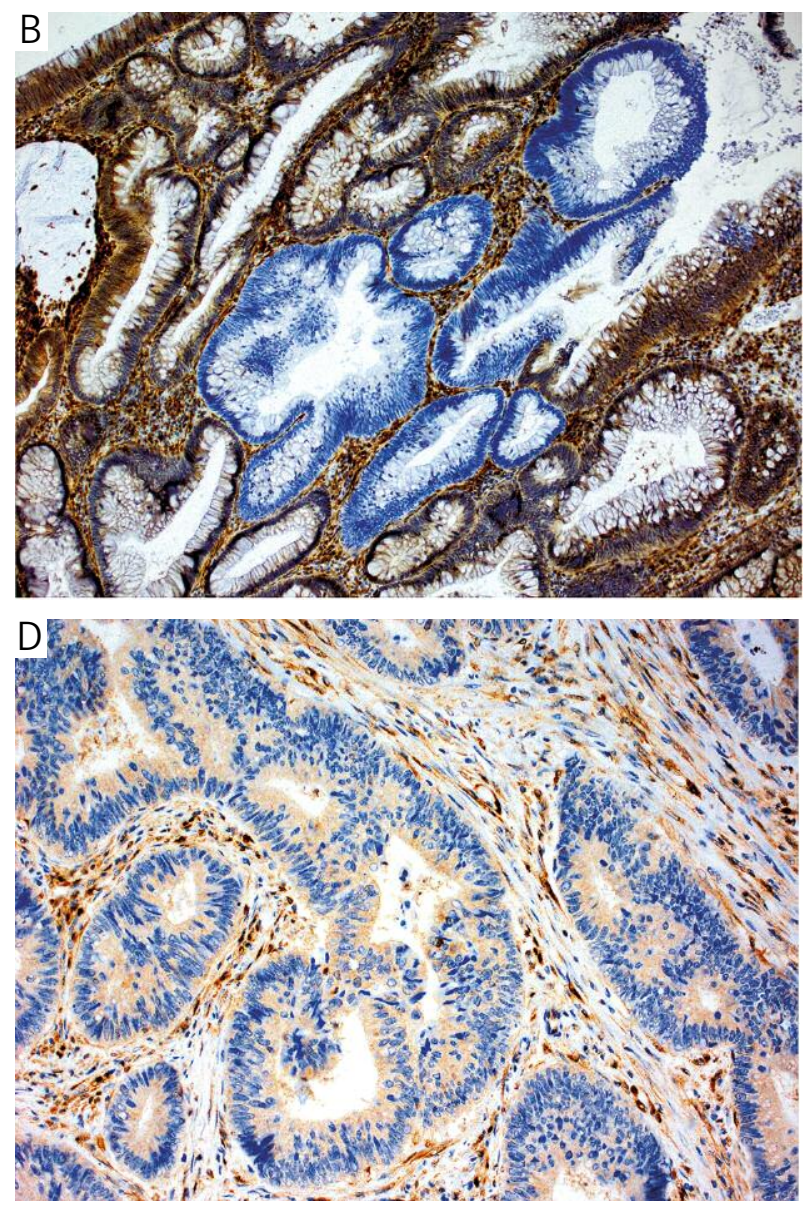

Fig. 1. Strong cytoplasmic and nuclear expression of PTEN in normal colonic mucosa (A); focal loss of PTEN expression in adenomatous polyp (B); adenocarcinoma with strong PTEN expression (C); adenocarcinoma with considerably reduced PTEN immunoreactivity with accompanying strong reaction in stromal component (D). IHC staining, original magnification $100 / 200 \times$ 
Furthermore, non-parametric Spearman's test confirmed a moderately strongly expressed $(\mathrm{R}=-0.53, \mathrm{p}=$ $0.003)$ negative correlation between polyp diameter and PTEN protein expression. There was also statistically significant lower expression of PTEN in polyps in comparison to normal intestinal mucosa $(\mathrm{p}=0.004)$. No correlation was found between PTEN expression in polyps and other clinical and histopathological features, including age, gender, shape, localization, dysplasia grade and histopathological type. A summary of the PTEN expression profiles in polyps is presented in Table II and their correlation with clinicopathological findings is presented in Table III.

\section{Expression of PTEN in colorectal adenocarci- noma}

In the group of 35 colorectal adenocarcinomas, normal PTEN expression was observed in 11 cases $(31.4 \%)$, decreased expression in 13 cases $(37.2 \%)$ and no expression in 11 samples $(31.4 \%)$. Cases with weak or absent expression were considered to be PTEN negative (22; $62.8 \%$ ) in further analysis (Table II). Colorectal carcinoma was characterized by statistically significant lower PTEN expression in comparison to normal adjacent mucosa $(p=0.00001)$ and adenomatous polyps $(p=0.005)$. Loss of PTEN was associated with tumor size and advanced TNM stage. Patients' age, gender, tumor location, nodal status and distant metastases did not correlate with PTEN immunohistochemical status (Table IV).

\section{Discussion}

Several studies have revealed that PTEN genetic aberrations are involved in the development of many cancers, including CRC $[5,8,9]$. However, it is also demonstrated that PTEN dysfunction, besides a genetic mechanism such as a promoter or gene mutation, may have an epigenetic background. That involves promoter hypermethylation, oxidative inactivation or suppression by microRNAs [16, 17]. Recent studies of both humans and mice with reduced PTEN gene dosage indicate that even partial loss of PTEN function is sufficient for promotion of some cancer types. The so-called obligatory PTEN haploinsufficiency theory formulated by Pandolfi [18] suggests that loss of $20 \%$ of activity of that protein leads to a noticeable increase of risk of cancer development. In the light of those findings a possibility of evaluation of minor changes in PTEN activity (expression) is of crucial importance.

PTEN expression profiles of adenomas and adenocarcinomas

Using the method of relative expression evaluation suggested by Perren [13] we have demonstrated a decrease or complete absence of PTEN protein expression in $41 \%$ and $5 \%$ of adenomatous polyps considered to be an early precancerous state of CRC. The loss of PTEN expression found by us in benign precancerous

Table II. PTEN expression profiles in normal intestinal mucosa, adenomatous polyps and colorectal adenocarcinoma

\begin{tabular}{lccc}
\hline PTEN EXPRESSION & \multicolumn{3}{c}{ No. OF CASES $(\%)$} \\
\cline { 2 - 4 } & NorMAL MUCOSA & ADENOMATOUS POLYPS & COLORECTAL ADENOCARCINOMA \\
\hline Loss & $0(0 \%)$ & $2(4.6 \%)$ & $11(31.4 \%)$ \\
\hline Decreased & $0(0 \%)$ & $18(40.9 \%)$ & $13(37.2 \%)$ \\
\hline Normal & $20(100 \%)$ & $24(54.6 \%)$ & $11(31.4 \%)$ \\
\hline Total negative & $0(0 \%)$ & $20(45.5 \%)$ & $24(68.6 \%)$ \\
\hline Total & $20(100 \%)$ & $44(100 \%)$ & $35(100 \%)$ \\
\hline
\end{tabular}

Table III. Comparison of clinicopathological findings by PTEN immunohistochemical status in the group of adenomatous polyps

\begin{tabular}{lcccc}
\hline & & \multicolumn{2}{c}{ PTEN EXPRESSION } & \multirow{2}{*}{ P VALUE } \\
\cline { 3 - 5 } & & $\begin{array}{c}\text { NEGATIVE } \\
(\mathbf{N}=20)\end{array}$ & $\begin{array}{c}\text { POSITIVE } \\
(\mathbf{N}=24)\end{array}$ & N.S.* \\
\hline Age & Year & 64.8 & 64.1 & N.S. \\
\hline Gender & $\mathrm{M} / \mathrm{F}$ & $7 / 13$ & $9 / 15$ & N.S \\
\hline Location & $\mathrm{C} / \mathrm{R}$ & $16 / 4$ & $17 / 7$ & N.S. \\
\hline Shape & $\mathrm{P} / \mathrm{SS} / \mathrm{S}$ & $10 / 1 / 9$ & $16 / 0 / 8$ & $0.008^{*}$ \\
\hline Diameter & $\mathrm{mm}$ & 13.4 & 6.7 & N.S. \\
\hline Dysplasia grade & $\mathrm{L} / \mathrm{M} / \mathrm{H}$ & $12 / 5 / 2$ & $16 / 6 / 0$ & \\
\hline
\end{tabular}

*p-value for Student's t-test

N.S. - not significant, $M / F-$ male/female, $C / R-$ colon/rectum, $P / S S / S$ - pedunculated/semi sessile/sessile, $L / M / H-l o w / m e d i u m / h i g h$ 
Table IV. Comparison of clinicopathological findings by PTEN immunohistochemical status in the group of adenocarcinoma

\begin{tabular}{lcccc}
\hline & & \multicolumn{2}{c}{ PTEN EXPRESSION } & P VALUE \\
\cline { 3 - 5 } & & $\begin{array}{c}\text { NEGATIVE } \\
(\mathbf{N}=25)\end{array}$ & $\begin{array}{c}\text { POsITIVE } \\
(\mathbf{N}=10)\end{array}$ & N.S.* \\
\hline Age & Year & 68.4 & 66.0 & N.S. \\
\hline Gender & $\mathrm{M} / \mathrm{F}$ & $12 / 13$ & $5 / 5$ & 0.011 \\
\hline $\mathrm{T}$ & $\mathrm{T} 1 / \mathrm{T} 2 / \mathrm{T} 3 / \mathrm{T} 4$ & $1 / 6 / 11 / 7$ & $3 / 4 / 3 / 0$ & 0.045 \\
\hline TNM stage & $\mathrm{I} / \mathrm{II} / \mathrm{III} / \mathrm{IV}$ & $7 / 7 / 7 / 4$ & $7 / 1 / 2 / 0$ & N.S. \\
\hline Lymph node invasion & Yes/No & $11 / 14$ & $2 / 8$ & N.S. \\
\hline Location & $\mathrm{C} / \mathrm{R}$ & $16 / 9$ & $4 / 6$ & N.S. \\
\hline Histological grade & $\mathrm{G} 1 / \mathrm{G} 2 / \mathrm{G} 3$ & $5 / 16 / 4$ & $3 / 7 / 0$ & \\
\hline
\end{tabular}

*p-value for Student's t-test

N.S. - not significant, $M / F-$ male/female, $C / R-$ colon/rectum

states suggests a significant role of that gene in the pathomechanism of large intestine cancer oncogenesis already in its early stages. Furthermore, the inverse correlation between PTEN expression and polyp physical dimensions recognized as a significant predictor of cancer transformation may suggest that PTEN dysfunction is one of the accumulating factors initiating a multistage neoplastic process. Consistently with our findings, Colakoglu et al. observed loss of cytoplasmic PTEN expression in $40 \%$ of adenomas - much more frequently than in carcinomas. They hypothesized that PTEN loss may be important in the adenoma-colon cancer sequence [19]. Similar results concerning nuclear PTEN were published by Hsu et al. Those authors revealed loss of PTEN expression in $4(44 \%)$ of 9 tested polyps [20]. They also reported, similarly to the present study, some well-defined differences in PTEN expression between normal colonic mucosa, adenomatous polyps and CRC. Such a relationship has been noted by other authors as well $[21,22]$.

\section{Correlation of PTEN expression and clinico- pathological characteristics}

Absence of or decreased PTEN expression was observed in almost $70 \%$ of adenocarcinomas in our series. Therefore we examined the correlation between the PTEN immunohistochemical status and some common clinicopathological parameters, including age, gender, tumor size and location, histological grade, nodal involvement and TNM staging. The analysis revealed that large tumor size and advanced stage are correlated with decreased or absent PTEN immunoreactivity. Similar observations were reported by some researchers $[20$, $22,23]$ but were not confirmed by others [19, 24]. On the other hand, a wide range of other features associated with PTEN dysfunction have been reported [20, 23], which were not confirmed in the present study, probably due to the relatively small group size.
In conclusion, loss of PTEN function may play an important role in both early and late stages of colorectal carcinogenesis. In the case of adenomatous polyps it may be a sign of a precancerous state - cancer transformation. During late carcinogenesis it is correlated with advanced stage and may be a predictor of poor prognosis - a conclusion that seems to be confirmed by the latest studies.

The authors declare no conflict of interest.

\section{References}

1. Didkowska J, Wojciechowska U, Zatonski W. Cancer in Poland in 2009. Warszawa 2011; 33.

2. Salmena L, Carracedo A, Pandolfi PP. Tenets of PTEN tumor suppression. Cell 2008; 133: 403-414.

3. Pérez-Tenorio G, Alkhori L, Olsson B, et al. PIK3CA mutations and PTEN loss correlate with similar prognostic factors and are not mutually exclusive in breast cancer. Clin Cancer Res 2007; 13: 3577-84

4. Xing M. Genetic alterations in the phosphatidylinositol-3 kinase/ Akt pathway in thyroid cancer. Thyroid 2010; 20: 697-706.

5. Li J, Yen C, Liaw D, et al. PTEN, a putative protein tyrosine phosphatase gene mutated in human brain, breast, and prostate cancer. Science 1997; 275: 1943-7.

6. Hollander MC, Blumenthal GM, Dennis PA. PTEN loss in the continuum of common cancers, rare syndromes and mouse models. Nat Rev Cancer 2011; 11: 289-301.

7. Tan M-H, Mester JL, Ngeow J, et al. Lifetime cancer risks in individuals with germline PTEN mutations. Clin Cancer Res 2012; 18: 400-7.

8. Chang JG, Chen YJ, Perng LI, et al. Mutation analysis of the PTEN/MMAC1 gene in cancers of the digestive tract. Eur J Cancer 1999; 35: 647-51.

9. Danielsen SA, Lind GE, Bjørnslett M, et al. Novel mutations of the suppressor gene PTEN in colorectal carcinomas stratified by microsatellite instability- and TP53 mutation-status. Hum Mutat 2008; 29: E252-262.

10. Karoui M, Tresallet C, Julie C, et al. Loss of heterozygosity on $10 \mathrm{q}$ and mutational status of PTEN and BMPR1A in colorectal primary tumours and metastases. Br J Cancer 2004; 90: $1230-4$ 
11. Goel A, Arnold CN, Niedzwiecki D, et al. Frequent inactivation of PTEN by promoter hypermethylation in microsatellite instability-high sporadic colorectal cancers. Cancer Res 2004; 64: 3014-21.

12. Waniczek D, Snietura M, Piglowski W, et al. Analysis of PTEN expression in large intestine polyps and its relation to the recognized histopathological and clinical risk factors for cancer development in this location. Wspolczesna Onkol 2012; 16: 310-5.

13. Perren A, Weng LP, Boag AH, et al. Immunohistochemical evidence of loss of PTEN expression in primary ductal adenocarcinomas of the breast. Am J Pathol 1999; 155: 1253-60.

14. Snietura M, Jaworska M, Mlynarczyk-Liszka J, et al. PTEN as a prognostic and predictive marker in postoperative radiotherapy for squamous cell cancer of the head and neck. PLoS ONE 2012; 7: e33396.

15. Razis E, Briasoulis E, Vrettou E, et al. Potential value of PTEN in predicting cetuximab response in colorectal cancer: an exploratory study. BMC Cancer 2008; 8: 234.

16. Wan X, Dennis AT, Obejero-Paz C, et al. Oxidative inactivation of the lipid phosphatase phosphatase and tensin homolog on chromosome ten (PTEN) as a novel mechanism of acquired long QT syndrome. J Biol Chem 2011; 286: 2843-2852.

17. Leslie NR, Foti M. Non-genomic loss of PTEN function in cancer: not in my genes. Trends Pharmacol Sci 2011; 32: 131-140.

18. Carracedo A, Alimonti A, Pandolfi PP. PTEN level in tumor suppression: how much is too little? Cancer Res 2011; 71: 629-633.

19. Colakoglu T, Yildirim S, Kayaselcuk F, et al. Clinicopathological significance of PTEN loss and the phosphoinositide 3-kinase/Akt pathway in sporadic colorectal neoplasms: is PTEN loss predictor of local recurrence? Am J Surg 2008; 195: 719-725.

20. Hsu CP, Kao TY, Chang WL, et al. Clinical significance of tumor suppressor PTEN in colorectal carcinoma. Eur J Surg Oncol 2011; 37: 140-147.

21. Lin MS, Huang JX, Chen WC, et al. Expression of PPAR-gamma and PTEN in human colorectal cancer: An immunohistochemical study using tissue microarray methodology. Oncology Letters 2011; 2: 1219-1224.

22. Li X-H, Zheng H-C, Takahashi H, et al. PTEN expression and mutation in colorectal carcinomas. Oncol Rep 2009; 22: 757 764.

23. Sawai H, Yasuda A, Ochi N, et al. Loss of PTEN expression is associated with colorectal cancer liver metastasis and poor patient survival. BMC Gastroenterol 2008; 8: 56.

24. Jang K-S, Song YS, Jang S-H, et al. Clinicopathological significance of nuclear PTEN expression in colorectal adenocarcinoma. Histopathology 2010; 56: 229-239.

\section{Address for correspondence}

Mirosław Śnietura

Tumor Pathology Department

Maria Sklodowska-Curie Memorial Cancer Center

and Institute of Oncology

Wybrzeże Armii Krajowej 15

44-101 Gliwice, Poland

tel. +48322789408

fax +48322789415

e-mail:mirek@snietura.net 